\title{
Seismic behaviour of RC building with raft foundation in the Ganges basin, India
}

\author{
J. S. Rajeswari ${ }^{1}$, Rajib Sarkar ${ }^{1}{ }^{*}$, Sekhar Chandra Dutta ${ }^{1}$, Jai Prakash Singh ${ }^{2}$ \\ and Ranjeet $\mathrm{Saw}^{3}$
}

\author{
${ }^{1}$ Department of Civil Engineering, Indian Institute of Technology (ISM), Dhanbad 826 004, India \\ ${ }^{2}$ Jharkhand Urja Sancharan Nigam Limited, Ranchi 834 004, India \\ ${ }^{3}$ Water Resources Department Madhya Pradesh, Bhopal 462 003, India
}

Many highly populated and important cities of India are situated in the Ganges basin. Deep alluvium deposit of this basin enhances the earthquake vulnerability of these cities due to amplification of seismic energies in the case of an earthquake. Raft foundations are generally provided for critical facility buildings due to their perceived effectiveness against differential settlement during earthquakes. However, the literature available on seismic behaviour of buildings with raft foundation considering soil deformability is relatively limited. In this context, a full three-dimensional finite element model of a four-storeyed building with raft foundation considering the typical layered soil profile of the Ganges basin has been developed in this study. The effects of different seismic parameters on the structural responses and moments induced in the raft have been studied with ground motions from 10 different earthquakes. Since the alluvium deposit of the Ganges basin is prone to get liquefied, effects of liquefaction of soil on the building with raft foundation have been considered simplistically. The results show that the raft foundation reduces the lateral displacement of the structure considerably. However, an increase in the vertical settlement of the raft in case of liquefiable soil is a matter of concern.

Keywords: Layered soil profile, raft footing, river basin, soil-structure interaction.

Due to the presence of soft alluvium deposits in the surficial layers, most parts of the Ganges basin are highly vulnerable to the amplification of seismic waves during earthquakes $^{1-3}$. This necessitates proper analysis and design of foundations under seismic loading conditions in such areas. Traditionally, foundations are designed without considering the interactive nature of footing and soil. Since the foundations are subjected to large inertial and kinematic loads in addition to vertical gravity loads during earthquakes ${ }^{4}$ this negligence may result in inaccurate estimation of forces and moments leading to unsafe design of foundations. To capture the real behaviour of

*For correspondence. (e-mail: rajib@iitism.ac.in) the system, analyses must be carried out considering the soil, foundation and superstructure as a single unit ${ }^{5-10}$.

The use of raft foundation is generally preferred for low-rise structures founded on soft ground, considering its beneficial role in reducing the differential settlement during earthquakes. The behaviour of the raft foundation during earthquakes is highly influenced by the subsoil profile, since the seismic forces get significantly modified by variation of the subsoil layers ${ }^{11}$. In the case of the Ganges basin, existence of soft alluvial deposits in the subsoil tends to amplify the seismic ground motion ${ }^{12}$, causing higher forces in the raft foundation. Hence a detailed study on the seismic behaviour of raft foundation in alluvial deposit is necessary.

The finite element method (FEM) of analysis is a wellaccepted numerical tool for solving various engineering problems. Wardle and Fraser ${ }^{13}$ utilized FEM to study the behaviour of uniformly loaded rectangular rafts resting on a homogeneous elastic layer. Surface elements were used for modelling interaction between the raft and the soil. The results indicated that the displacement and bending moment of the raft foundation are highly influenced by variation in rigidity of the raft, length-tobreadth ratio, depth of the soil layer and Poisson's ratio. King and Chandrasekaran ${ }^{14}$ presented a finite element procedure for analysing a plane frame supported on a combined footing. The frame and combined footing were modelled using beam-bending elements and the soil using plane rectangular elements. The raft-soil interface was simulated using zero-thickness friction elements. Later, King and Chandrasekaran ${ }^{15}$ developed a full threedimensional finite element formulation for studying the immediate and long-term behaviour of the space frameraft-soil system. Brown and $\mathrm{Yu}^{16}$ examined the effect of sequence of construction on the interaction behaviour and found that the effective stiffness of a building during construction is about half the stiffness of the completed structure. Tahghighi and Rabiee $^{17}$ demonstrated the importance of considering foundation flexibility for the safe and economical design of structures under earthquake loading.

Liquefaction of soil is one of the leading causes of damage to structures during earthquakes, in case structures 


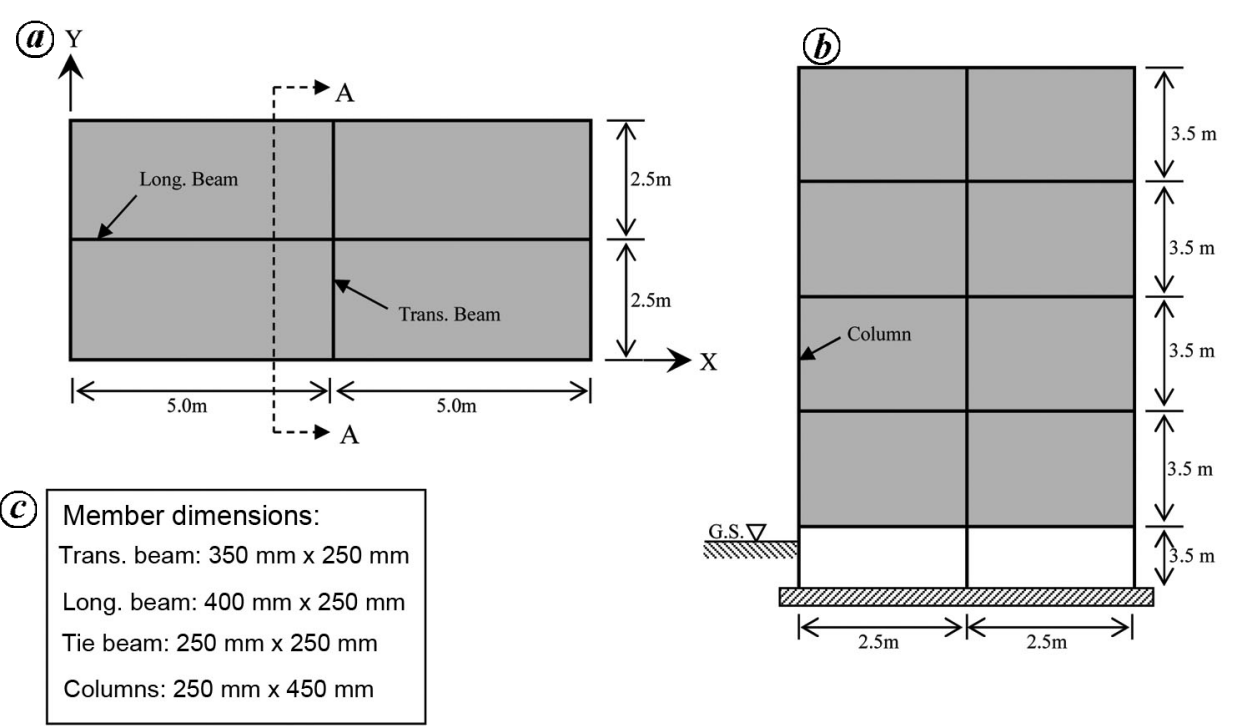

Figure 1. Details of the building considered for analysis: $\boldsymbol{a}$, Plan of the building. $\boldsymbol{b}$, Side elevation (section A-A). $\boldsymbol{c}$, Member dimensions.

are founded on saturated sand or silt (especially in waterfront areas or in areas with high water table). During earthquake loading, soil particles rearrange themselves into a densely packed position causing the pore water pressure to increase. The magnitude of the excess pore pressure significantly depends on the arrangement of soil particles during shaking ${ }^{18}$. When this excess pore pressure matches with effective stress in the soil, the soil loses substantial strength until the excess pore water pressure dissipates. In addition to the stiffness and strength reduction, damping of soils will also increase during liquefaction. The values may reach as high as $20 \%$, as reported by Lombardi and Bhattacharya ${ }^{19}$. Hence, considering the effects of liquefaction in the design of the raft foundation is important, especially when soil deposits consist of liquefiable layers. The liquefied soil filters out high frequencies of ground motion and amplifies long-period components of the shaking. This causes development of elongated oscillation cycles at the sites. Due to softening of soil during liquefaction, chances of vertical as well as the differential settlement of building structures are also high. Various studies have demonstrated that simplified empirical methods are not efficient in determining liquefaction-induced displacements of structures supported on shallow foundations ${ }^{20-22}$. Wang et al. $^{23}$ and Kumar and Kumari ${ }^{24}$ studied the seismic performance of shallow foundation in liquefiable soil. Travasarou et al. ${ }^{25}$, and Luque and Bray ${ }^{26}$ analysed the responses of buildings damaged as the result of liquefaction during the 1999 Kocaeli and 2011 Christchurch earthquakes considering the effects of soil-structure interaction (SSI). Karimi and Dashti ${ }^{27}$ carried out threedimensional finite element analyses to study the seismic response of structures supported on a shallow foundation in liquefiable soil and compared it with that of centrifuge results. Bray and Dashti ${ }^{28}$ suggested a few recommendations for estimating the settlement of buildings supported on a shallow foundation. Johari and $\mathrm{Sabzi}^{29}$ carried out a reliability analysis of foundation settlement using the stochastic response surface method and random finiteelement method. Fotopoulou et al. ${ }^{30}$ studied the effect of liquefaction-induced differential settlement on RCframed buildings of varying heights. Dashti ${ }^{31}$ carried out centrifuge tests and noted that significant settlement occurs mainly due to strong shaking. Sarkar et al. ${ }^{32}$ suggested that alluvium deposits of the Ganges basin are highly liquefiable. A study ${ }^{33}$ on seismic behaviour of buildings with isolated footings has been recently reported ${ }^{33}$. However, the literature on seismic behaviour of the raft foundation in liquefiable soil deposits is rare.

The highlights of the present study are as follows: (1) Seismic analyses of an RC framed building with raft foundation considering a full three-dimensional model of the soil-structure-raft system. (2) Evaluation of the effects of various seismic parameters on the building with raft foundation. (3) Comparison of the structural responses/forces for the building with the raft foundation and isolated footing for various earthquake loadings. (4) Analysis of the effects of liquefaction of soil layers due to various earthquake time histories.

\section{Details of building considered for the study}

In this study, a two-bay four-storey $(\mathrm{G}+3) \mathrm{RC}$ frame having a storey height of $3.5 \mathrm{~m}$ has been considered ${ }^{34}$. It consists of two bays in both directions, with a bay width of $5 \mathrm{~m}$ and $2.5 \mathrm{~m}$ in the $X$ - and $Y$-directions respectively. Figure 1 shows the plan, elevation and member dimensions of the building considered. The thickness of the 

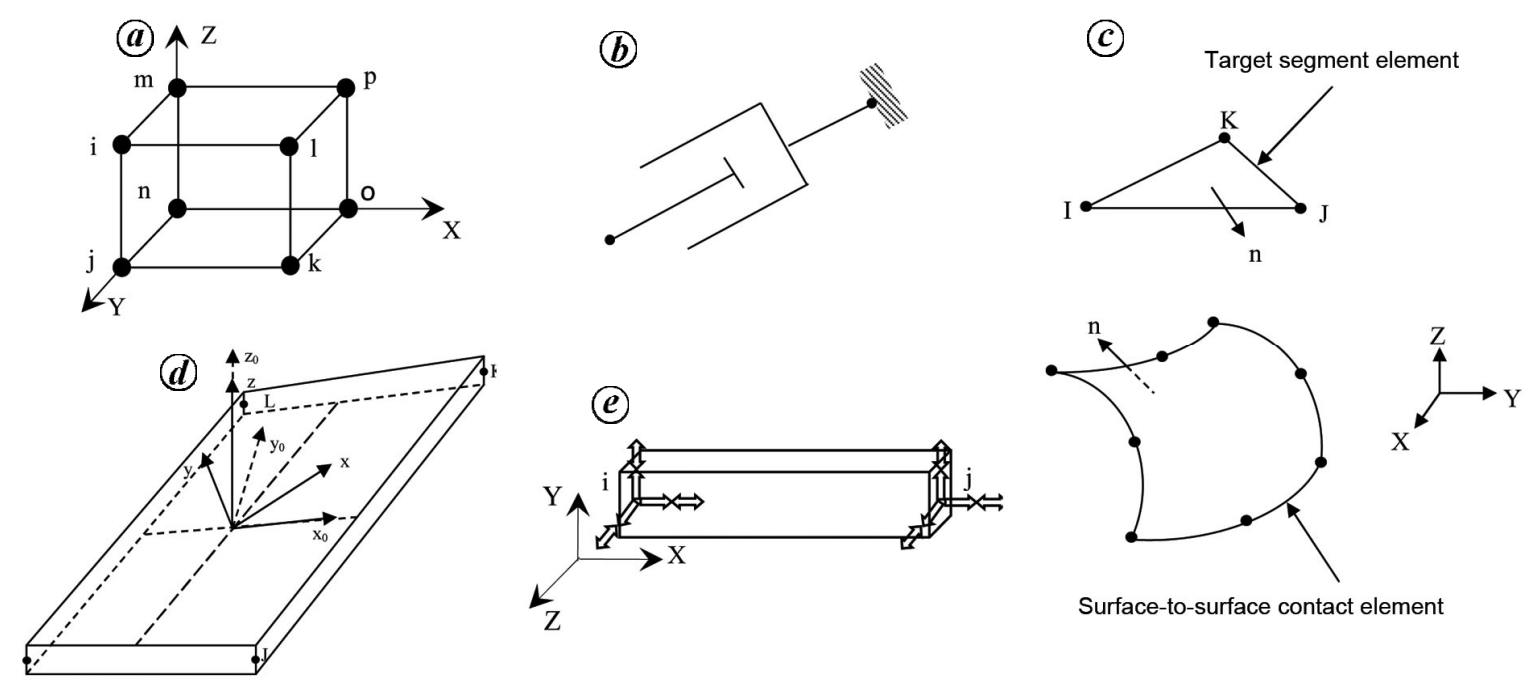

Figure 2. Finite elements used in the study. $\boldsymbol{a}$, Eight-node solid element for modelling of soil; $\boldsymbol{b}$, Viscous dashpot element; $\boldsymbol{c}$, Interface (surface-to-surface) element; $\boldsymbol{d}$, Shell element; $\boldsymbol{e}$, Beam element.

roof and floor slabs is $100 \mathrm{~mm}$. M25 grade of concrete and Fe415 grade of reinforcing steel are considered. The building frame is modelled as 3D space frame along with raft foundation and soil layers. For modelling of the frame structure, 3D beam elements have been adopted. The floor slab and raft have been modelled using shelltype elements. The soil is modelled with eight-node brick elements. General-purpose finite element software package ANSYS (Version 15.0) has been employed for modelling of building-raft and soil system ${ }^{35}$.

\section{Details of modelling in ANSYS}

In this study, soil and superstructure were modelled integrally with appropriate interface material. Both soil and concrete are considered to be linear elastic materials. To eliminate the boundary effects, the soil domain was considered to be twice the length or width of the superstructure. The radiation boundary was considered using viscous dashpots at the lateral boundaries in both horizontal and vertical directions ${ }^{36}$. The bottom boundary was considered to be fixed.

\section{Frame modelling}

The frame was modelled as an assemblage of beam elements (Beam188) with six degrees of freedom at each node (three translational and three rotational degrees of freedom).

\section{Modelling of raft}

The raft has been modelled using SHELL181 element of ANSYS. SHELL181 is suitable for analysing thin to moderately thick shell structures. It is a four-noded element with six degrees of freedom at each node (three translational and three rotational degrees of freedom).

\section{Modelling of soil}

The soil has been treated as an isotropic, homogeneous and elastic half-space medium. The soil medium below the raft was modelled using the eight-node brick element (SOLID45) having three translational degrees of freedom at each node.

\section{Modelling of interface between raft and soil}

The interface characteristic between the raft and supporting soil beneath was established using TARGE170 and CONTA174 elements. TARGE170 is used to represent various $3 \mathrm{D}$ target surfaces for the associated contact elements. The contact elements overlay the solid, shell or line elements, which form the boundary of a deformable body and are potentially in contact with the target surface. This target surface is discretized by a set of target segment elements and paired with its associated contact surface via a shared real constant set. One can impose forces and moments on the target element. Figure 2 shows all the finite elements used for modelling of the soil-structure-raft system.

\section{Details of soil profile}

The present study is specific to the soil profile obtained in the Ganges basin in India. It is observed that the soil profile is quite similar along the Ganges basin. For example, in Table 1, typical soil profiles of three major 
Table 1. Comparison of typical soil profiles of different cities/towns along the River Ganga

\begin{tabular}{|c|c|c|c|c|c|}
\hline City/town & $\begin{array}{l}\text { Stratum } \\
\text { no. }\end{array}$ & Basic description & Thickness (m) & $\begin{array}{l}\text { SPT value } \\
\quad\left(N_{1}\right)_{60}\end{array}$ & $\begin{array}{c}\text { Shear wave } \\
\text { velocity } V_{\mathrm{s}}(\mathrm{m} / \mathrm{s})\end{array}$ \\
\hline \multirow[t]{4}{*}{ Patna } & I & Soft silty clay & $0-7.5$ & $3-5$ & $110-140$ \\
\hline & II & Loose sandy silt & $7.5-12$ & $5-11$ & $140-180$ \\
\hline & III & Loose sandy silt & $12-27$ & $15-25$ & $190-230$ \\
\hline & IV & Stiff clayey silt & $27-50$ & $25-50$ & $230-300$ \\
\hline \multirow[t]{4}{*}{ Kolkata } & I & Filled-up soil & $0-2$ & $2-5$ & $100-140$ \\
\hline & II & Silty clay/sandy silt & $2-14$ & $5-15$ & $140-200$ \\
\hline & III & Medium to stiff clayey silt & $14-28$ & $15-30$ & $190-250$ \\
\hline & IV & Dense silty sand & $28-50$ & $30-50$ & $250-300$ \\
\hline \multirow[t]{4}{*}{ Haldia } & I & Soft silty clay & $0-2$ & $2-5$ & $100-140$ \\
\hline & II & Soft clayey silt & $2-12$ & $4-12$ & $120-180$ \\
\hline & III & Sandy silt/silty sand & $14-28$ & $15-30$ & $190-250$ \\
\hline & IV & Clayey silt/silty clay & $28-50$ & $20-60$ & $210-310$ \\
\hline
\end{tabular}

Table 2. Generalized soil profile

\begin{tabular}{|c|c|c|c|c|c|}
\hline $\begin{array}{l}\text { Stratum } \\
\text { no. }\end{array}$ & Basic description & Thickness (m) & $\begin{array}{c}\text { SPT } \\
\text { value }\left(N_{1}\right)_{60}\end{array}$ & $\begin{array}{l}\text { Unit weight, } \\
\gamma\left(\mathrm{kN} / \mathrm{m}^{3}\right)\end{array}$ & $\begin{array}{c}\text { Shear wave } \\
\text { velocity } V_{\mathrm{s}}(\mathrm{m} / \mathrm{s})\end{array}$ \\
\hline I & Soft silty clay & 2.0 & 3 & 19.1 & 144 \\
\hline II & Soft clayey silt & 5.0 & 2 & 18.2 & 126 \\
\hline IIIA & Loose sandy silt & 12.5 & 8 & 18.0 & 160 \\
\hline IIIB & Medium dense silty sand & 3.0 & 8 & 19.0 & 160 \\
\hline IV & Stiff clayey silt & 2.5 & 8 & 18.4 & 200 \\
\hline $\mathrm{V}$ & Medium dense silty sand & 3.0 & 28 & 19.0 & 243 \\
\hline VI & Medium stiff silty clay & 15.5 & 11 & 18.0 & 222 \\
\hline VII & Stiff clayey silt & 9.5 & 32 & 18.5 & 317 \\
\hline VIII & Very dense silty sand & 12.0 & $>100$ & 20.0 & $>500$ \\
\hline
\end{tabular}

cities/towns (viz. Patna, Kolkata, and Haldia) along the lower-middle stretch of River Ganga are compared. From the table, it may be observed that the primary layers of soil profiles are almost similar for the cities along the Ganges.

Considering this fact, the study considers the soil profile of a project site at Haldia $\left(22^{\circ} 4^{\prime} 0.0228^{\prime \prime} \mathrm{N}\right.$ and $\left.88^{\circ} 4^{\prime} 11.3124^{\prime \prime} \mathrm{E}\right)$ in West Bengal, India ${ }^{32}$. This site is near the Ganges and comprises superficial deposits (alluvium and river terrace deposits) underlain by clay formation. The site condition is similar to those encountered in the eastern regions of the Ganges basin. The detailed subsoil profile comprised of eight different layers.

Table 2 presents details of the soil profile and soil parameters. It may be mentioned that stratum no. VIII is considered to be the engineering bedrock for the study, since Standard Penetration Test (SPT) value $\left(N_{1}\right)_{60}$ is more than 100 , indicating the presence of very strong strata. The raft footing is assumed to be resting on top of the stratum no. II having cohesion $c=23 \mathrm{kPa}$, compression index, $C_{\mathrm{c}}=0.25$, and initial void ratio $=0.9$. The shear wave velocity of soil layers has been calculated $(\mathrm{m} / \mathrm{s})$, based on the Japanese highway code (JRA) relations using the SPT value $(N)$ as given in eqs (1) and (2) respectively.

$$
\begin{aligned}
& V_{\mathrm{s}}=80 N^{1 / 3} \text { for sand, } \\
& V_{\mathrm{s}}=100 N^{1 / 3} \text { for clay. }
\end{aligned}
$$

Though correlations between $V_{\mathrm{S} 30}$ and $N$ value are available for northern regions of the Ganges basin, no reliable study has been reported for the eastern regions (Bihar and West Bengal). Moreover, the correlations proposed by $\mathrm{JRA}^{37}$ are widely accepted internationally and have been used by researchers for various studies. Hence, it may be considered that there will be no significant changes in the results presented here.

The schematic diagram of the building with raft foundation and layered soil profile, and the corresponding model developed in ANSYS are shown in Figures 3 and 4 respectively.

The present study will give a broad idea about the effect of alluvium deposits of the Ganges basin on seismic response of a typical $\mathrm{RC}$ building with raft foundation. Table 1 indicates that primarily soil profiles are similar with minor variations. However, to arrive at generalized understanding and conclusions, a series of building frames with different soil profiles must be studied. 


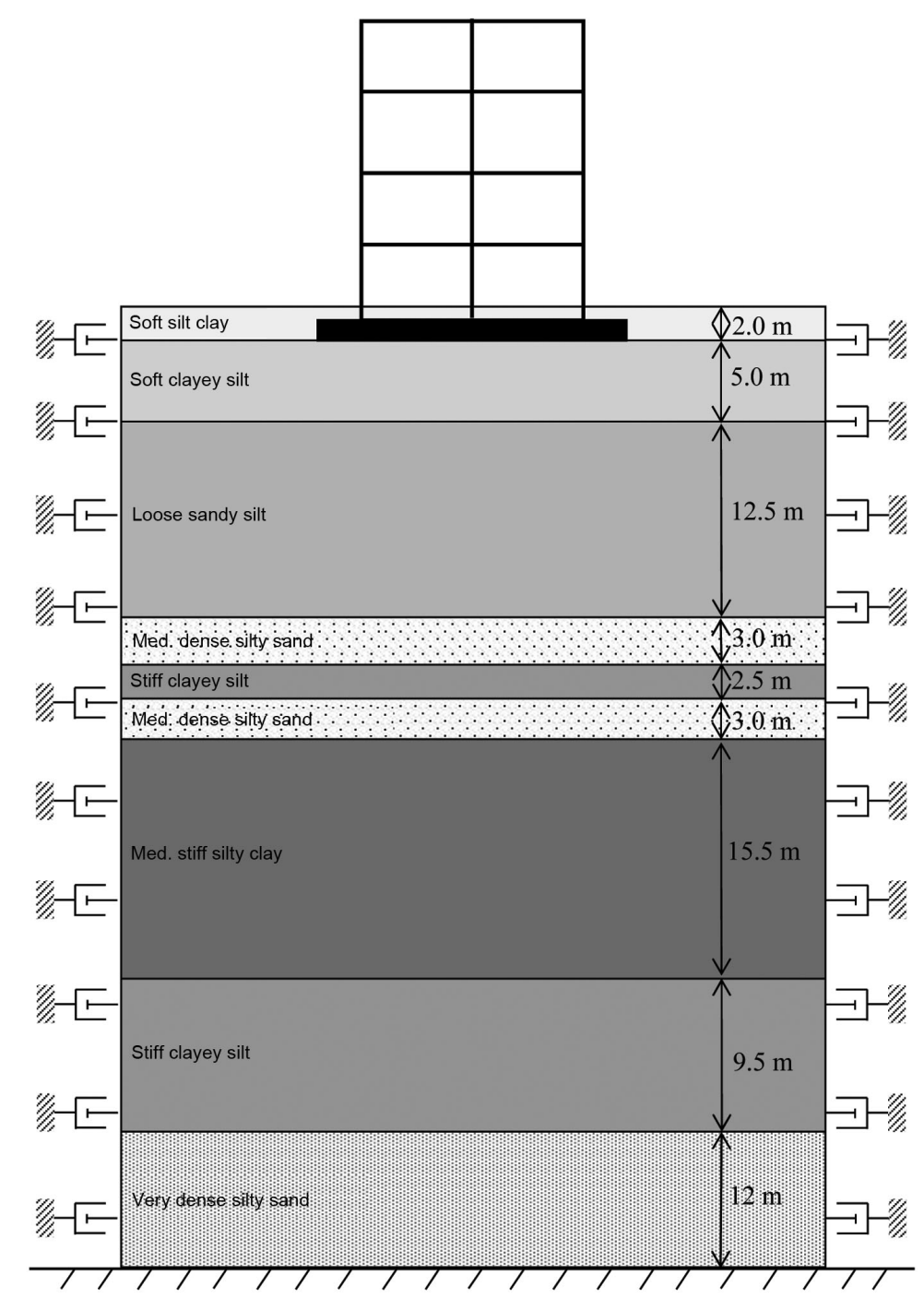

Figure 3. Schematic diagram of the building, raft and layered soil profile.

\section{Earthquake time histories considered}

Acceleration time histories of 12 different earthquakes having different peak ground acceleration (PGA) values and predominant frequency as mentioned have been considered for analyses (Table 3). Earthquakes have been selected covering a wide range of PGA values and dominant frequencies. These earthquake time histories are considered as bedrock motions.

Table 4 shows values of PGA and predominant frequency of three Himalayan earthquakes. It may be noted that the PGA values and predominant frequencies of the earthquake time histories (Table 3) considered in the present study cover those of the Himalayan earthquakes.

It may also be noted that seismic behaviour of the soil-foundation-structure system mainly depends on the strong-motion parameters of earthquake time histories. Since the present study covers a wide range of parameters for the same (covering Himalayan earthquakes as well), the results presented here will comply with Himalayan earthquakes as well.

\section{Results and discussion}

\section{Effect of soil amplification}

One-dimensional ground response analyses have been carried out for the convolution of bedrock motion to obtain the free-field motion for the soil profile considered. The soil layers have been considered as linear elastic material and stratum no. VIII has been considered as the elastic bedrock (since shear wave velocity is maximum, i.e. $>500 \mathrm{~m} / \mathrm{s}$ and the velocity is almost proportionately increasing with further depth) for the analyses. The open-source software package DEEPSOIL (Version 6.1) has been used. Table 5 shows the PGA, maximum 


\section{RESEARCH ARTICLES}

amplification ratio and predominant frequency values of the free-field motion.

The table indicates that the soil layers modify the bedrock motion to a great extent. In most of the earthquakes considered, amplification of about 1.5 times the bedrock motion has been observed. However, for some earthquakes (viz. Nahanni 1985 and Whittier Narrows 1987), deamplification has also been observed. The characteristics of the free-field motion have been changed drastically, as may be observed from the dominant

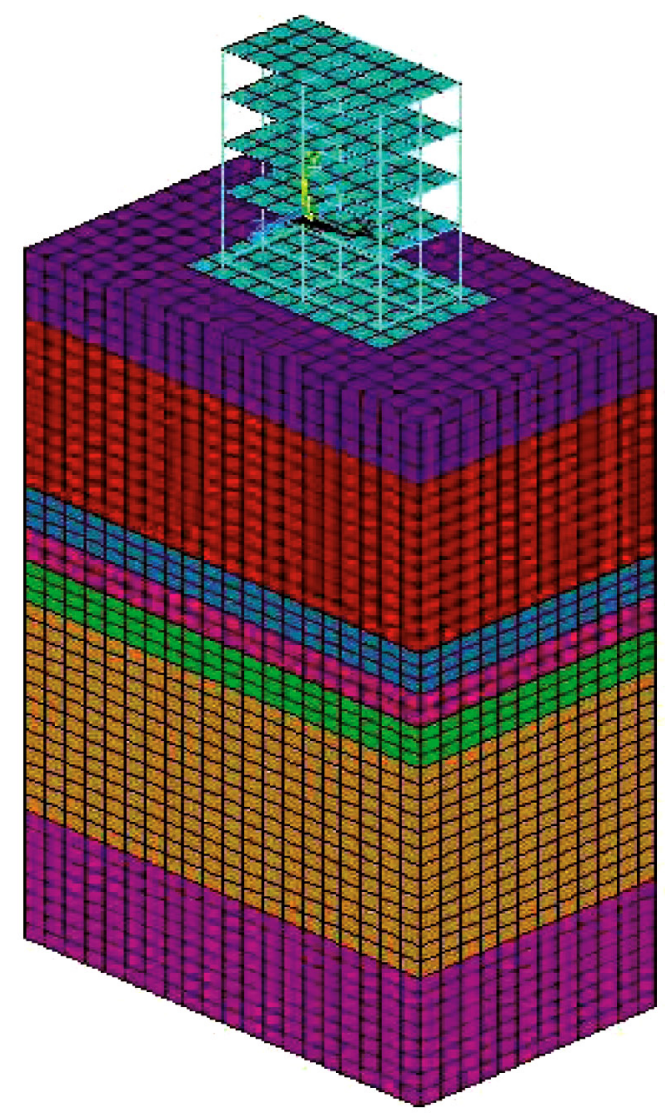

Figure 4. Three-dimensional finite element model of the building, raft and layered soil profile.

Table 3. Earthquake time histories of bedrock motion considered for the study

\begin{tabular}{lcc}
\hline Earthquake and year of occurrence & $\begin{array}{c}\text { PGA } \\
(\mathrm{g})\end{array}$ & $\begin{array}{c}\text { Predominant } \\
\text { frequency }(\mathrm{Hz})\end{array}$ \\
\hline Chi-Chi, 1999 & 0.18 & 0.80 \\
El-Centro, 1940 & 0.32 & 2.16 \\
Coyote, 1976 & 0.12 & 2.40 \\
Imperial Valley, 1979 & 0.17 & 3.24 \\
Mammoth Lake, 1980 & 0.43 & 2.42 \\
Loma Gilroy, 1989 & 0.17 & 3.94 \\
Nahanni, 1985 & 0.15 & 16.06 \\
Northridge, 1994 & 0.22 & 5.01 \\
Parkfield, 2004 & 0.36 & 2.63 \\
Whittier Narrows, 1987 & 0.19 & 6.41 \\
\hline
\end{tabular}

frequencies of the free-field motions presented in Table 5. This confirms the effects of the alluvium deposits of the Ganges basin in modifying the earthquake histories.

\section{Comparison of peak displacement for building with raft and isolated foundation}

To have a better physical insight, the same building model with isolated footing was studied for the sake of comparison with the response obtained due to the raft foundation. In Figure $5 a$, peak displacements for the building with isolated footing and that with raft foundation have been compared. For this, free-field motions of the considered earthquakes have been taken for the isolated footing condition, while for raft foundation bedrock motions of the enlisted earthquakes have been considered. These motions have been applied to the threedimensional building-raft and layered soil model as input base motions. It is observed that for some of the earthquake time histories, buildings with isolated footings behave in a flexible manner showing higher displacement values than buildings with raft foundation. This goes with the common perception that buildings with raft foundation are comparatively rigid than those with isolated footing under seismic conditions and hence safer. However, for some earthquakes, buildings with the raft foundation show higher displacements. This may be due to the tuning of frequencies of earthquakes with the natural frequency of three-dimensional building foundation and soil model, and modification of earthquake time histories in the presence of the soil layers. So, the results demonstrate the influence of SSI on the overall response of building structures even for the raft foundation.

\section{Comparison of peak acceleration values}

Figure $5 b$, absolute maximum peak acceleration at the roof level of the building structure for various earthquakes have been compared. It is observed that the peak acceleration for the building is maximum for the Loma Gilroy earthquake (1989). It may also be noted from Table 5 that, for the present soil profile, maximum amplification in PGA of the input bedrock motion has been noticed for the Loma Gilroy earthquake (1989). The effect of this amplification of ground motion is exhibited

Table 4. List of Himalayan earthquakes

\begin{tabular}{lccc}
\hline Earthquake & Station location & PGA (g) & $\begin{array}{c}\text { Predominant } \\
\text { frequency (Hz) }\end{array}$ \\
\hline 1999 Uttarkashi & $30^{\circ} 48^{\prime} \mathrm{N} / 78^{\circ} 36^{\prime} \mathrm{E}$ & 0.25 & 7.2 \\
1995 Chamba & $32^{\circ} 33^{\prime} \mathrm{N} / 76^{\circ} 07^{\prime} \mathrm{E}$ & 0.14 & 11.6 \\
1999 Chamoli & $30^{\circ} 24^{\prime} \mathrm{N} / 79^{\circ} 20^{\prime} \mathrm{E}$ & 0.20 & 12.1 \\
\hline
\end{tabular}


Table 5. Details of free field motion obtained from ground response analyses

\begin{tabular}{lccc}
\hline Earthquake and year of occurrence & PGA $(\mathrm{g})$ & Amplification ratio & Predominant frequency $(\mathrm{Hz})$ \\
\hline Chi-Chi, 1999 & 0.28 & 1.54 & 1.31 \\
El-Centro, 1940 & 0.46 & 1.43 & 1.57 \\
Coyote, 1976 & 0.19 & 1.53 & 2.51 \\
Imperial Valley, 1979 & 0.23 & 1.37 & 2.36 \\
Mammoth Lake, 1980 & 0.43 & 1.00 & 2.63 \\
Loma Gilroy, 1989 & 0.27 & 1.61 & 2.27 \\
Nahanni, 1985 & 0.09 & 0.64 & 5.14 \\
Northridge, 1994 & 0.26 & 1.21 & 5.01 \\
Parkfield, 2004 & 0.55 & 1.54 & 2.64 \\
Whittier Narrows, 1987 & 0.15 & 0.80 & 6.41 \\
\hline
\end{tabular}
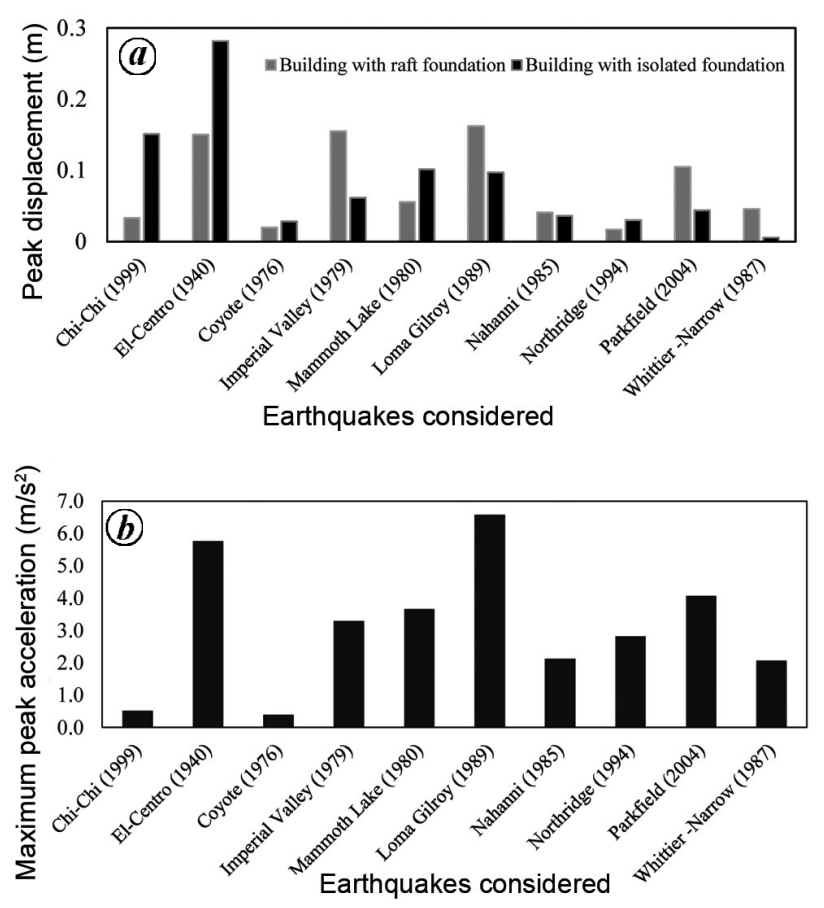

Figure 5. $\boldsymbol{a}$, Comparison of peak displacements of building with raft and isolated foundation. $\boldsymbol{b}$, Comparison of maximum peak acceleration of various earthquakes considered.

by the peak structural acceleration for the earthquake and hence understandably other structural forces. It is also observed from the comparison that for earthquakes whose PGA values are less and dominant frequencies are away from the fundamental frequency of the structural system, the peak acceleration values are less.

\section{Distribution of moments in the raft}

The raft foundation of the building is expected to undergo different distribution of moments for different earthquakes. This section discusses the distribution of moments along the length and width of the raft at the noted critical time (i.e. at the instant of time at which peak acceleration at the roof level is maximum). This will help design the raft foundation and estimate the maximum forces in the raft for various earthquake motions.

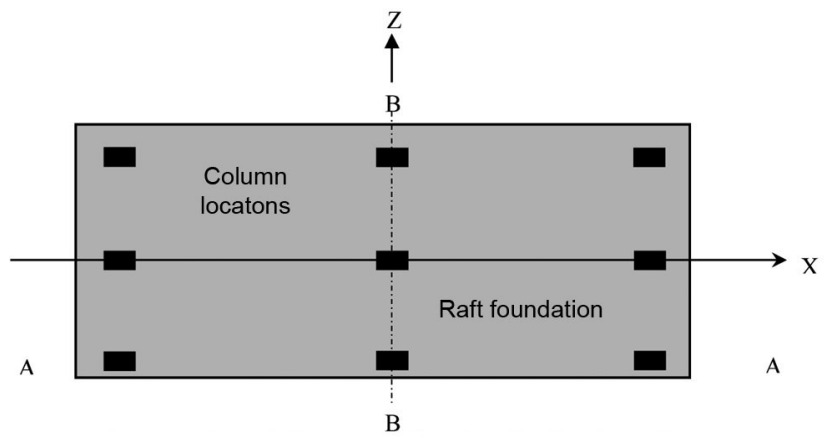

Figure 6. Section considered for presenting the distribution of moments.

Section considered for distribution of moments: The distribution of moments in the raft has been reported for two sections (Figure 6): one along the length (section $\mathrm{X}-\mathrm{X}$ ) and one along the width (section $\mathrm{B}-\mathrm{B}$ ).

Bending moment $\left(M_{x}\right)$ distribution along section $A-A$ : Figure $7 a$ shows the variation of bending moment $\left(M_{x}\right)$ along section $\mathrm{A}-\mathrm{A}$ for various earthquakes considered in the study. Bending moment variations along the length indicate that appreciable bending moment is developed at the location of columns of the building, which makes these particular locations more vulnerable during earthquakes. On moving away from the column position, the bending moment decreases rapidly to its minimum values at nodes next to column nodes for most of the earthquakes considered. It is observed that the bending moment is maximum for the Loma Gilroy earthquake (1989), as the maximum amplification in PGA for the considered soil profile was observed for this earthquake. Hence the soil profile and earthquake parameters will influence the bending moment distribution and also peak moment values in the raft foundation. Incorporation of the effect of soil flexibility only can recognize the occurrence of such a considerable bending moment.

Bending moment $\left(M_{z}\right)$ distribution along section $A-A$ : Figure $7 b$ shows bending moment $\left(M_{z}\right)$ distribution along section A-A. This varies almost in a similar fashion as that of $M_{x}$ along the length of the raft, having maximum values at the column position and gradually decreasing on 

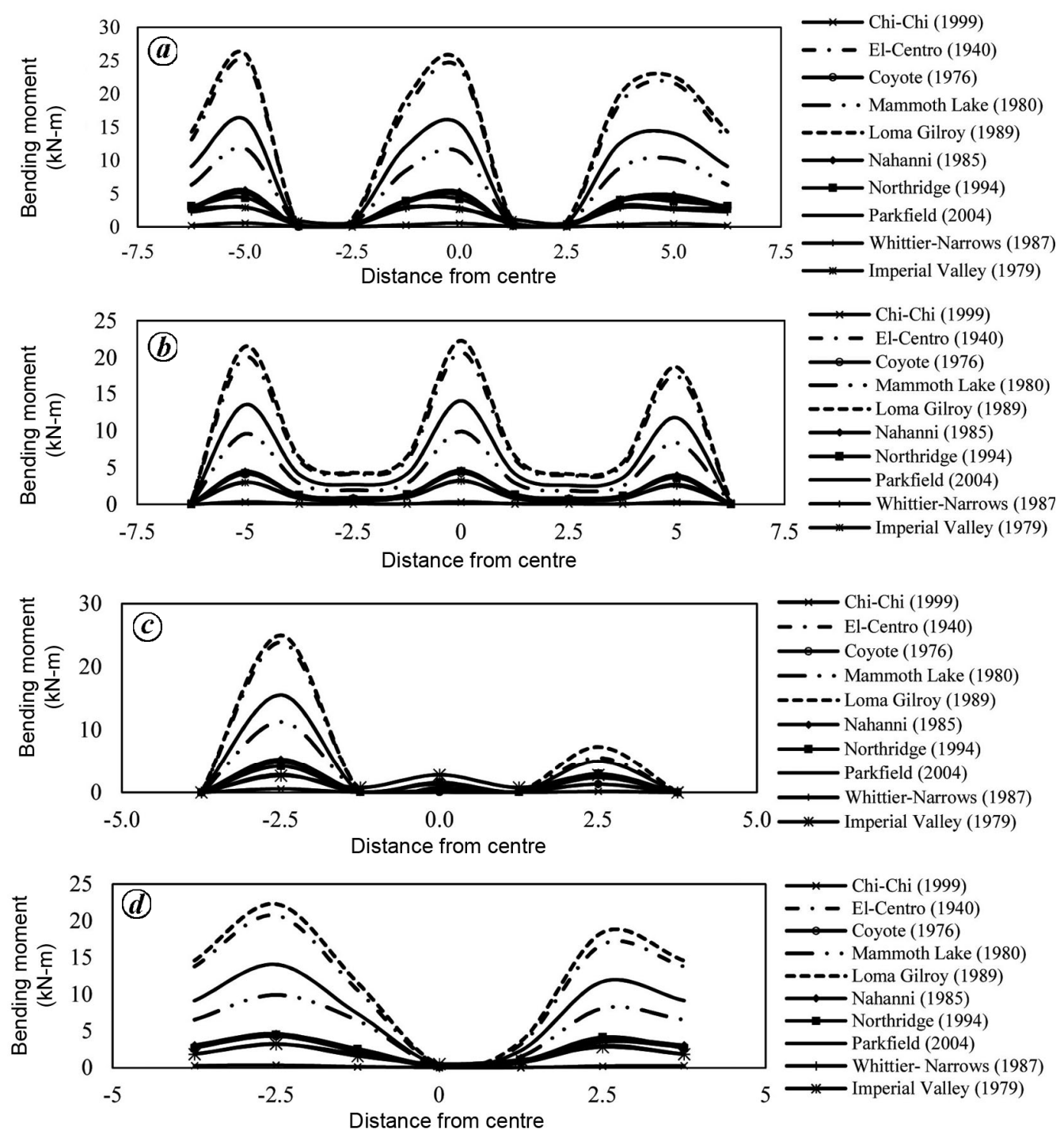

Figure 7. Comparison of the moments: (a) $M_{x}$ along section A-A, (b) $M_{z}$ along section A-A, (c) $M_{x}$ along section B-B and (d) $M_{z}$ along section B-B of the raft for various earthquakes.

moving away from the column position. The moment $M_{z}$ at the beginning and end positions of the raft decreases rapidly to negligible values, unlike the variation of $\left(M_{x}\right)$.

Bending moment $\left(M_{x}\right)$ distribution along section $B-B$ : Figure $7 c$ shows bending moment $\left(M_{x}\right)$ distribution along the width of the foundation. It may be noted that the earthquake loading has been applied along the width of the building. So, the moment is maximum on one side of the raft foundation and vanishes at the centre due to symmetry of the building considered. The maximum values of moment in the raft are in the same range for both sections $\mathrm{A}-\mathrm{A}$ and $\mathrm{B}-\mathrm{B}$.

Bending moment $\left(M_{z}\right)$ distribution along section $B-B$ : Figure $7 d$ shows bending moment $\left(M_{z}\right)$ along the width of the footing. The variation of moment almost follows a similar fashion as $M_{x}$, having maximum values at the corner columns and negligible values at the central column.

Comparison of maximum moment $\left(M_{x}\right)$ in the raft: Figure $8 a$ compares absolute values of maximum moment $M_{x}$ in the raft caused by various earthquakes. It is observed that the earthquake with the highest amplification for the present soil profile causes maximum moment in the raft. In the present study, the Loma Gilroy earthquake (1989) had maximum amplification of bedrock motion. In accordance with the Loma Gilroy earthquake motion, the raft of the building experienced maximum moment. It implies that even if the raft provides rigidity to the structural system, the effect of amplification due to soil strata has an influence on the seismic behaviour of 
the building with raft foundation. This is especially significant if the building structure is founded on alluvium deposits, such as in the Ganges basin.

Comparison of maximum moment $\left(M_{z}\right)$ in the raft: Figure $8 b$ compares absolute maximum moment $\left(M_{z}\right)$ values for various earthquakes. It is observed that the values of $M_{z}$ are mostly less than those observed for $M_{x}$ for any particular earthquake. However, the trend for maximum moment by the earthquakes remains the same for both $M_{x}$ and $M_{z}$. In this case also, it is observed that the earthquake which is amplified more produces more moment in the raft, even if PGA value of bedrock motion is less for that particular earthquake.

\section{Seismic behaviour of the building with raft considering liquefaction}

Liquefaction of soil layers beneath the foundation during seismic loading is one of the root causes of failure of various building structures. Hough and Bilham ${ }^{38}$ studied the effects of site response of the Ganges basin from various macroseismic observations and indicated liquefaction susceptibility at various locations of saturated sediments.

Consideration of liquefaction of soil remains one of the challenging tasks for design engineers when structures are founded on a saturated soil medium. The present study is extended to consider the effect of liquefaction on the founding soil. For this, the water table is considered to be at the ground surface. From preliminary

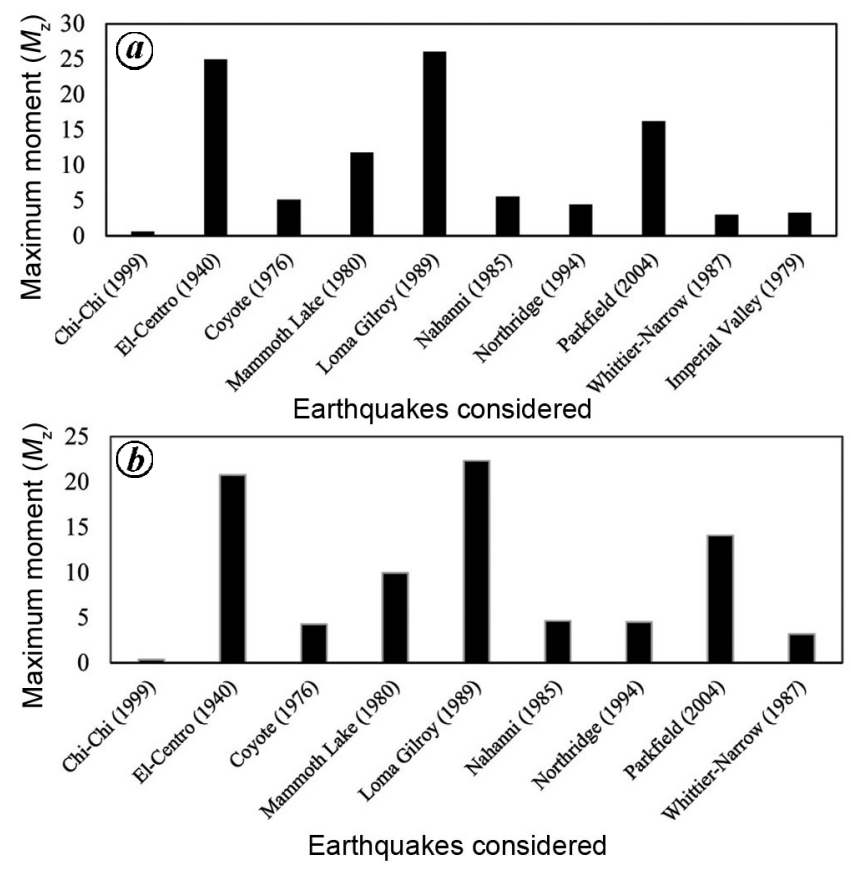

Figure 8. $\boldsymbol{a}, \boldsymbol{b}$, Comparison of maximum moment (a) $M_{x}$ and (b) $M_{z}$ of the raft for various earthquakes. liquefaction analyses ${ }^{39,40}$, it has been determined that the layers I and II of the present soil profile are highly liquefiable $^{32}$. To approximately consider the effect of liquefaction of soil, the modulus of liquefiable layers has been reduced to (one-tenth) of their original elastic modulus following Brandenberg ${ }^{41}$, considering the SPT values of the layers.

\section{Effect of liquefaction on peak displacement}

Peak displacements of the building are compared for two cases, i.e. (a) without considering liquefaction of soil as discussed earlier in the text, and (b) considering liquefaction of soil for various earthquake time histories considered. Figure 9 provides a comparison of peak displacement values of the building.

The figure depicts considerable increase in peak displacement of the building with the liquefaction of top layers of soil. It may be mentioned here that liquefaction of the soil medium elongates the lateral period of the building foundation system; so it may behave differently compared to a building founded on soil without liquefaction, under dynamic loading conditions. It is observed that the building peak displacement is maximum for the El Centro earthquake. This may be because the dominant frequency of the modified El Centro motion at liquefied condition tunes with the fundamental frequency of the building foundation system.

\section{Effect of liquefaction on vertical displacement of raft footing}

For the earthquakes considered, it is observed that the raft settles vertically quite significantly with liquefaction of the founding soil. This may be due to the reduction of stiffness of the soil following liquefaction. Vertical deformations along the length of the raft have been compared for both the cases, i.e. (a) without consideration of liquefaction and (b) with liquefaction (Figure 10). From

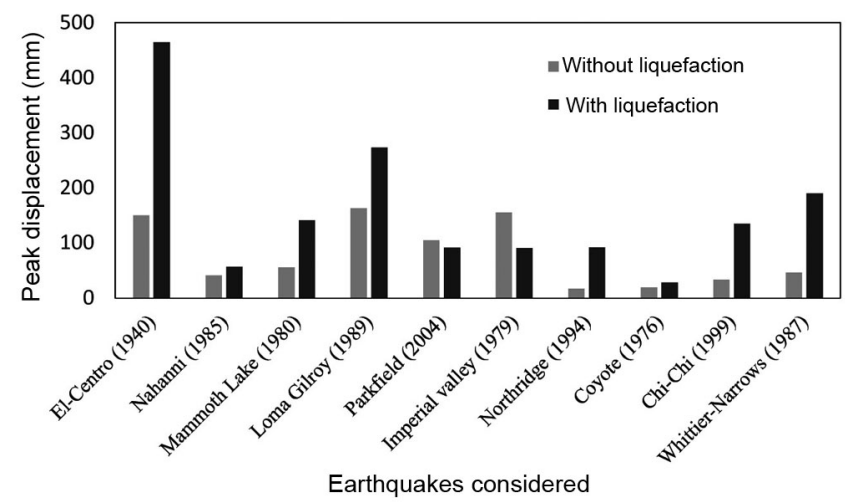

Figure 9. Comparison of peak displacement of the building structure founded on liquefiable soil and non-liquefiable soil. 

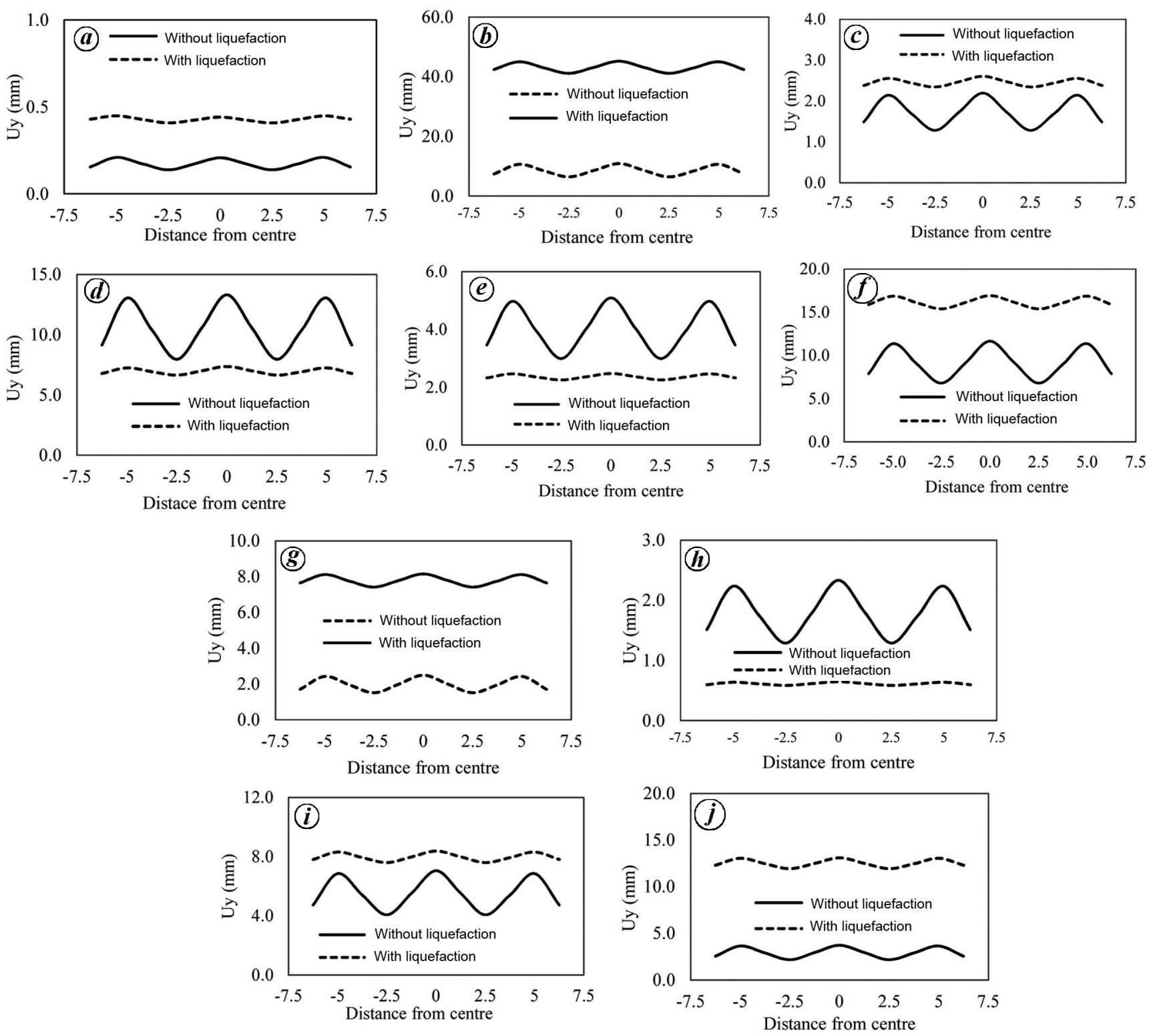

Figure 10. $\boldsymbol{a}-\boldsymbol{j}$, Effect of liquefaction on vertical deformation of raft for various earthquakes. (a) Chi-Chi earthquake (1999), (b) El-Centro earthquake (1940), (c) Coyote earthquake (1976), (d) Imperial Valley earthquake (1979), (e) Mammoth Lake earthquake (1980), $(\boldsymbol{f})$ Loma Gilroy earthquake (1989), (g) Nahanni earthquake (1985), (h) Northridge earthquake (1994), (i) Parkfield earthquake (2004) and (j) Whittier Narrows earthquake (1987).

Figure 10, it is again be inferred that liquefaction of the founding soil significantly increases the vertical settlement of the raft and in effect the full building structure. It may be observed from Figure 10 that the increase in vertical deformation of the raft is in the range $30-50 \%$ compared to that of the building founded on non-liquefiable soil. Moreover, after consideration of liquefaction, vertical deformation along the length of raft becomes flattered having little difference between its peak and trough, which indicates that the raft as a whole is settling down vertically. Hence the possibility of differential settlement of the building with raft foundation is unlikely even in case of liquefiable soil.

\section{Effect of liquefaction on lateral displacement of raft footing}

For various earthquakes, lateral displacement along the length of the raft has been evaluated for both the cases, i.e. (a) without consideration of liquefaction, and (b) with liquefaction. For maximum earthquakes, after consideration of liquefaction, lateral displacement increases compared to its previous value. However, it may be noted that the lateral displacement values are not as high as vertical deformation values. Therefore, it may be concluded that consideration of liquefaction of the topsoil layers increases the vulnerability of the building structure under seismic 

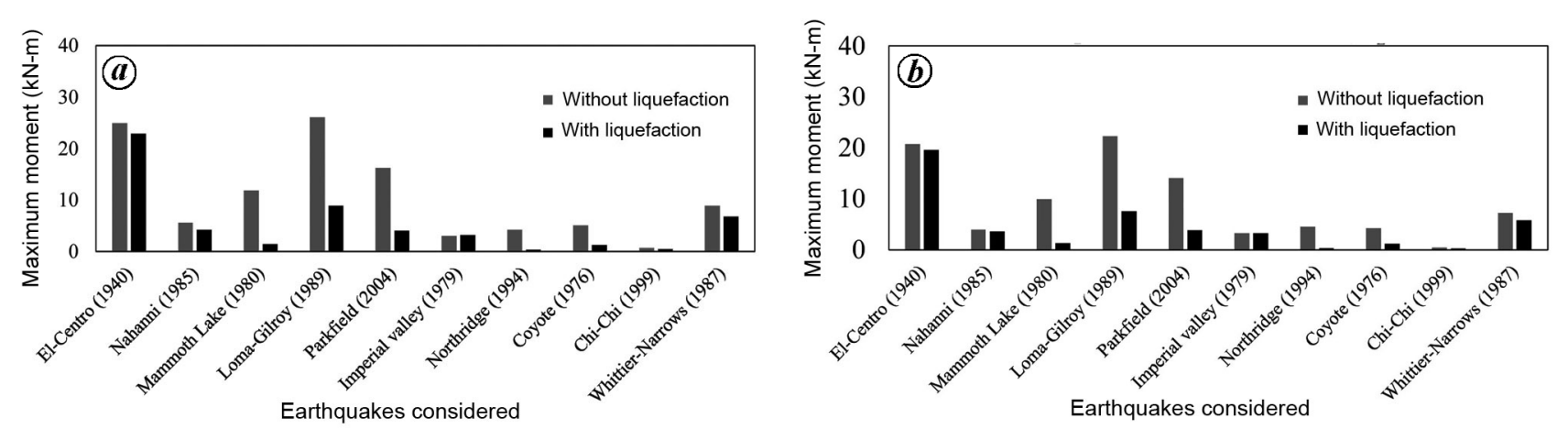

Figure 11. Comparison of maximum moments $(\boldsymbol{a})\left(M_{x}\right)$ and $(\boldsymbol{b})\left(M_{z}\right)$ in the raft for various earthquakes.

loading conditions, even if the structure is founded on raft foundations. The designer has to ensure that the building with raft does not settle more than the permissible value, if the soil layers are liquefiable.

\section{Effect of liquefaction on maximum moment in raft footing}

Maximum moments in the raft $\left(M_{x}\right)$ and $\left(M_{z}\right)$ have been evaluated on with consideration of liquefaction of soil (Figure 11). The maximum moment in the raft decreases with consideration of liquefaction of the soil for almost all the earthquakes considered for the analyses. Since liquefaction of the soil layers beneath the foundation reduces the stiffness of the founding soil making the system more flexible, less moment is induced in the raft though the uniform vertical deformation is more. Both the moment values, i.e. $M_{x}$ and $M_{z}$ follow the same trend after considering the effect of liquefaction of the soil layers.

\section{Conclusion}

The Ganges basin of India is vulnerable to earthquake loadings due to the presence of soft soil deposits. This is one of the highly populated regions of the world. This study presents seismic analyses of a full threedimensional building on a raft foundation, founded on a realistic eight-layered soil profile similar to alluvium deposits of the Ganges basin. For carrying out seismic analyses, acceleration time-history motions of 10 different earthquakes having different PGA values and predominant frequencies have been considered. The important conclusions are as follows. (1) The alluvium deposits of the Ganges basin significantly change the characteristics of the ground motion. Significant amplification of the ground motion has been observed. (2) Variation of bending moments (both $M_{x}$ and $M_{z}$ ) along the length of the raft depicts an appreciable increase in value at the column location making these particular locations vulnerable under seismic conditions. Variation of bending moments (both $M_{x}$ and $M_{z}$ ) along the width of raft also exhibits a similar trend. (3) The earthquake which amplifies more for a particular soil profile produces greater moment in the raft, even if PGA of the bedrock motion is less for the earthquake time history. (4) Due to liquefaction of the soil layer, there is about a $30-50 \%$ increase in peak displacement of the building for the earthquake motions considered. (5) Though the raft provides rigidity to the system, the problem of vertical settlement remains a matter of concern for the practising designers, if the soil is liquefiable.

This study may prove useful to develop insights into the seismic behaviour of common residential buildings with raft foundation on alluvium deposits of the Ganges basin, and may help in arriving at a better design of the foundation of such structures. The present work can further be extended to understand the effect of foundation types on the seismic behaviour of buildings considering isolated footings as adapted in Sarkar et al. ${ }^{33}$.

1. Shiuly, A., Kumar, V. and Narayan, J. P., Computation of ground motion amplifica6tion in Kolkata megacity (India) using finitedifference method for seismic microzonation. Acta Geophys., 2014, 62(3), 425-450.

2. Shiuly, A. and Narayan, J. P., Deterministic seismic microzonation of Kolkata city. Nat. Hazards, 2012, 60(2), 223-240.

3. Govindaraju, L. and Bhattacharya, S., Site-specific earthquake response study for hazard assessment in Kolkata city, India. Nat. Hazards, 2012, 61(3), 943-965.

4. Poulos, H. G., Tall building foundations: design methods and applications. Innovative Infrastructure Solutions, 2016, 1(1), 10.

5. Ghosh, B. and Madabhushi, S. P. G., Centrifuge modelling of seismic soil-structure interaction effects. Nucl. Eng. Design, 2007, 237(8), 887-896.

6. Bhattacharya, K., Dutta, S. C. and Dasgupta, S., Effect of soilflexibility on dynamic behaviour of building frames on raft foundation. J. Sound Vib., 2004, 274(1-2), 111-135.

7. Halkude, S. A., Kalyanshetti, M. G. and Barelikar, S. M., Seismic response of RC frames with raft footing considering soil-structure interaction. Int. J. Curr. Eng. Technol., 2014, 4(3), 1424-1431.

8. Dutta, S. C. and Roy, R., A critical review on idealization and modeling for interaction among soil-foundation-structure system. Comput. Struct., 2002, 80(20-21), 1579-1594. 
9. Saha, R., Dutta, S. C. and Haldar, S., Seismic response of soil-pile raft-structure system. J. Civ. Eng. Manage., 2015, 21(2), 144164.

10. Storie, L., Soil-foundation-structure interaction in the earthquake performance of multi-storey buildings on shallow foundations. Ph D dissertation, University of Auckland, New Zealand, 2017.

11. Cubrinovski, M. and McCahon, I., Foundations on deep alluvial soils. Technical Report, University of Canterbury, Christchurch, New Zealand, 2011.

12. Semblat, J. F., Dangla, P., Kham, M. and Duval, A. M., Seismic site effects for shallow and deep alluvial basins: In-depth motion and focusing effect. Soil Dyn. Earthquake Eng., 2002, 22(9-12), 849-854.

13. Wardle, L. J. and Fraser, R. A., Methods for raft foundation design including soil-structure interaction. In Symposium on Raft Foundations, Perth, Australia, 1975.

14. King, G. J. W. and Chandrasekaran, V. S., Interaction analysis of rafted multistoried space frame resting on the inhomogeneous clay structure. In International Conference on FEM in Engineering, University of New South Wales, Australia, 1974.

15. King, G. J. W. and Chandrasekaran, V. S., Interactive analysis using a simplified soil model. In International Symposium on Soil-Structure Interaction, Roorkee, 1977.

16. Brown, P. T. and Yu, S. K., Load sequence and structurefoundation interaction. J. Struct. Eng., 1986, 112(3), 481-488.

17. Tahghighi, H. and Rabiee, M., Influence of foundation flexibility on the seismic response of low-to-mid-rise moment-resisting frame buildings. Scientia Iranica, Transaction A: Civil Engineering, 2017, 24(3), 979-992.

18. Seed, H. B., Soil liquefaction and cyclic mobility evaluation for level ground during earthquakes. J. Geotech. Geoenviron. Eng. ASCE, 1979, 105(2), 201-255.

19. Lombardi, D. and Bhattacharya, S., Modal analysis of pile-supported structures during seismic liquefaction. Earthquake Eng. Struct. Dyn., 2014, 43(1), 119-138.

20. Macedo, J. and Bray, J. D., Key trends in liquefaction-induced building settlement. J. Geotech. Geoenviron. Eng., ASCE, 2018, 144(11), 0401876.

21. Ziotopoulou, K. and Montgomery, J., Numerical modeling of earthquake-induced liquefaction effects on shallow foundations. In Proceedings of the 16th World Conference on Earthquake Engineering, Santiago, Chile, 2017.

22. Karimi, Z., Bullock, Z., Dashti, S., Liel, A. and Porter, K., Influence of soil and structural parameters on liquefaction-induced settlement of foundations. In Proceedings of the 3rd International Conference on Performance-based Design in Earthquake Geotechnical Engineering (PBD-III), Vancouver, Canada, 2017.

23. Wang, H., Guangyun, G. and Jian, S., Numerical study on settlement of building with shallow foundation under earthquake loading. In Geo-Shanghai International Conference, Singapore, 2018 , pp. 251-260.

24. Kumar, A. and Kumari, S., Numerical modeling of shallow foundation on liquefiable soil under sinusoidal loading. Geotech. Geol. Eng., 2019, 37(2), 517-532.

25. Travasarou, T., Bray, J. D. and Sancio, R. B., Soil-structure interaction analyses of building responses during the 1999 Kocaeli earthquake. In Proceedings of the 8th US National Conference on Earthquake Engineering, EERI, California, USA, 2006.
26. Luque, R. and Bray, J. D., Dynamic analyses of two buildings founded on liquefiable soils during the Canterbury earthquake sequence. J. Geotech. Geoenviron. Eng., 2017, 143(9), 04017067.

27. Karimi, Z. and Dashti, S., Seismic performance of shallow founded structures on liquefiable ground: validation of numerical simulations using centrifuge experiments. J. Geotech. Geoenviron. Eng., 2016, 142(6), 04016011.

28. Bray, J. D. and Dashti, S., Liquefaction-induced movements of buildings with shallow foundations. In International Conference on Recent Advances in Geotechnical Earthquake Engineering and Soil Dynamics, San Diego, California, USA, 2010.

29. Johari, A. and Sabzi, A., Reliability analysis of foundation settlement by stochastic response surface and random finite-element method. Scientia Iranica, Transaction A: Civil Engineering, 2017, 24(6), 2741-2751.

30. Fotopoulou, S., Karafagka, S. and Pitilakis, K., Vulnerability assessment of low-code reinforced concrete frame buildings subjected to liquefaction-induced differential displacements. Soil Dyn. Earthquake Eng., 2018, 110, 173-184.

31. Dashti, S., Toward evaluating building performance on softened ground, Ph D thesis, University of California, Berkeley, 2009.

32. Sarkar, R., Bhattacharya, S. and Maheshwari, B. K., Seismic requalification of pile foundations in liquefiable soils. Indian Geotech. J., 2014, 44(2), 183-195.

33. Sarkar, R., Dutta, S. C., Saw, R. and Singh, J. P., Effect of differential settlement on seismic response of building structure. Proceedings of the Institution of Civil Engineers-Municipal Engineer, 2018, pp. 1-10; doi:https://doi.org/10.1680/jmuen. 18.00032 .

34. Agrawal, P. and Shrikhande, M., Earthquake Resistant Design of Structures, PHI Learning Pvt Ltd, New Delhi, India, 2006.

35. ANSYS, User Manual, version 15.0, Swanson Analysis Systems Inc., Houston, PA, USA, 2015.

36. Lysmer, J. and Kuhlemeyer, R. L., Finite dynamic model for infinite media. J. Eng. Mech. Div., 1969, 95, 859-878.

37. Japan Road Association. Specifications for highway bridges, Part V: Earthquake resistant design. JRA, 1980.

38. Hough, S. E. and Bilham, R., Site response of the Ganges basin inferred from re-evaluated macroseismic observations from the 1897 Shillong, 1905 Kangra, and 1934 Nepal earthquakes. J. Earth Syst. Sci., 2008, 117(S2), 773-782.

39. Boulanger, R. W. and Idriss, I. M., Evaluating cyclic failure in silts and clays. In Geotechnical Earthquake Engineering Satellite Conference, Osaka, Japan, 2005.

40. Idriss, I. M. and Boulanger, R. W., Semi-empirical procedures for evaluating liquefaction potential during earthquakes. Soil Dyn. Earthq. Eng., 2006, 26(2-4), 115-130.

41. Brandenberg, S. J., Behavior of pile foundations in liquefied and laterally spreading ground. Ph D thesis, University of California, Davis, USA, 2005.

ACKNOWLEDGEMENT. J. S. Rajeswari, J. P. Singh and Ranjeet Saw thank Ministry of Human Resource Development, Government of India, for financial support.

Received 7 June 2019; revised accepted 29 November 2019

doi: $10.18520 / \mathrm{cs} / \mathrm{v} 118 / \mathrm{i} 5 / 759-770$ 